\title{
Cardiopulmonary bypass weaning difficulty due to anomalous origin of coronary artery -A case report-
}

\author{
Hyun Ju Jung, Jong Bun Kim, Kyong Shil Im, Chung Hee Joo, and Jae Myeong Lee \\ Department of Anesthesiology and Pain Medicine, Uijeongbu St. Mary's Hospital, The Catholic University of Korea, Uijeongbu, Korea
}

We report a case of hemodynamic instability after aortic valve replacement, due to the anomalous origin of the right coronary artery. During the cardiopulmonary bypass weaning process, hemodynamic instability occurred. The cause was not identified at first, and compression of the anomalous right coronary artery was thought to be the culprit, thereafter. (Korean J Anesthesiol 2013; 64: 533-535)

Key Words: Anomalous origin of coronary artery, Aortic valve replacement, Cardiopulmonary bypass weaning.

Difficult cardiopulmonary bypass (CPB) weaning, during the cardiac surgery, makes it difficult for the physicians. The cause of difficult weaning should be found, but sometimes it is difficult.

Aortic valve replacement with tissue valve has rare complications. Difficult weaning, due to the aberrant coronary artery, happens very rarely, and it is difficult to think that the aberrant artery might be the culprit for difficult weaning. Anesthesiologists should know of this possibility preoperatively, and if not, useless management could be done.

\section{Case Report}

A 76-year-old male with $160 \mathrm{~cm}$ in height and $58 \mathrm{~kg}$ in weight, respectively, was admitted for surgery with known aortic stenosis. He has a previous history of diabetes, hypertension and asthma. He had taken glimepiride, telmisartan, furosemide and bisoprolol. Preoperative echocardiography exams revealed the followings: aortic valve calcification and severe stenosis, a decreased left ventricular systolic function, trivial tricuspid regurgitation and ejection fraction of $40-45 \%$. In a coronary artery angiography, right coronary artery was originated from the left coronary sinus (Fig. 1). However, compression of the coronary arteries by major vessels was not revealed. Coronary computed tomography (CT) was not checked. The patient was scheduled for aortic valve replacement.

At the operating theatre, routine noninvasive and invasive blood pressure monitoring, electrocardiography (EKG), pulse oximetry and bispectral index monitoring was established. Anesthetic induction was done under target-controlled infusion (TCI) of propofol and remifentanil. Then pulmonary artery catheter and transesophageal echocardiography (TEE) probe

Received: May 10, 2012. Revised: 1st, July 13, 2012; 2nd, August 16, 2012. Accepted: August 31, 2012.

Corresponding author: Jae Myeong Lee, M.D., Department of Anesthesiology and Pain Medicine, Uijeongbu St. Mary's Hospital, The Catholic University of Korea, 65-1, Geumo-dong, Uijeongbu 480-130, Korea. Tel: 82-31-820-3087, Fax: 82-31-821-8449, E-mail: jaemng@catholic.ac.kr C) This is an open-access article distributed under the terms of the Creative Commons Attribution Non-Commercial License (http:// creativecommons.org/licenses/by-nc/3.0/), which permits unrestricted non-commercial use, distribution, and reproduction in any medium, provided the original work is properly cited. 


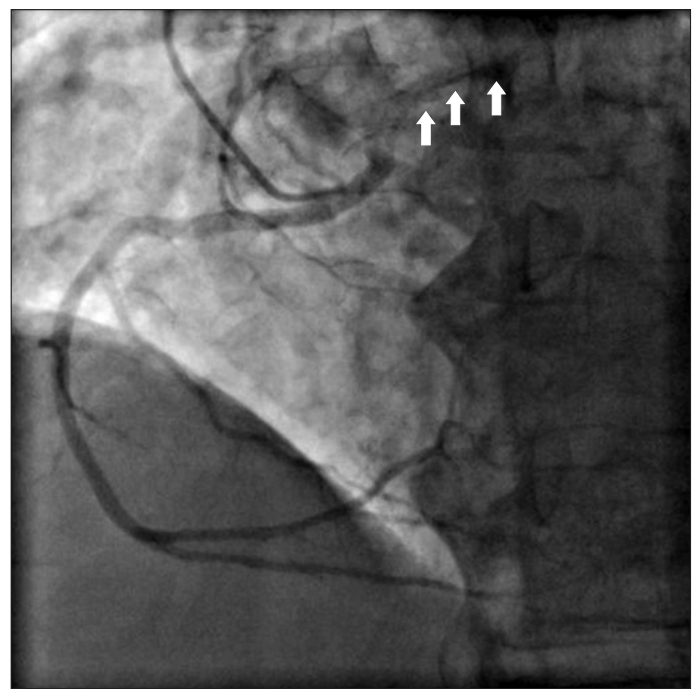

Fig. 1. Preoperative coronary angiography. During injection of the contrast dye into the right coronary artery, the left coronary artery is shown simultaneously (arrows). Therefore, instead of using Judkin coronary catheter right 4 , we used left 4 to take a photograph of the anomalous origin of right coronary artery.

were inserted. TEE revealed severe calcified and stenotic aortic valve, trivial tricuspid regurgitation and a good regional wall motion. Until the CPB initiation, vital signs were maintained well.

At the time of the operation, aortic valve and annulus were severely calcified and both coronary arteries were originated from the left coronary sinus, but have different ostia. Aortic valve was replaced with $19 \mathrm{~mm}$ St. Jude Medical xenoartic bioprosthesis Epic (St. Jude Medical, Minnesota, USA) and the surgery were done without specific event. During cardiopulmonary bypass weaning, blood pressure and cardiac output were unstable. The changes of ST segment in EKG were detected. These situations were repeated for about 30 minutes, and dopamine and norepinephrine infusion were started. TEE showed intermittent hypokinesia of inferoposterior wall motion. Air was not detected, and nitroglycerin infusion was not effective. Epinephrine was infused and intraaortic balloon pump (IABP) was inserted. Cardiac wall motion was progressively normalized and vital signs were stabilized. The total surgery and CPB time was 360 minutes and 161 minutes, respectively. The patient was transferred to coronary care unit after surgery, and vital signs were also stable. Anomalous origin of the right coronary was considered as the culprit for the difficult weaning process. IABP was removed the next day, and the patient was discharged without any special events.

\section{Discussion}

Poor ventricle function, regional wall motion abnormalities, or significant unexplained arrhythmias after aortic valve surgery should suspect poor myocardial protection, coronary insufficiency due to mechanical cause, coronary spasm, coronary air/particle emboli, protamin/transfusion reactions, and anomalous coronary artery [1-4]. Since the aortic valve has been replaced with a stentless tissue valve, a number of mechanical obstructions in the coronary arteries have been reported. During the surgery, distal suture line, near the coronary artery ostium, Teflon pledget, vessel kinking or torsion, after coronary artery reimplantation, obstructs the coronary artery [4-8]. Clinically significant air embolism occurs rarely and is usually self-limiting and resolved quickly. Particulates emboli, such as a calcified aortic valve, papillary muscle, or aortic vegetation, immediately impair the hemodynamic at the beginning of coronary perfusion and change the EKG. Sometimes, hemodynamic fluctuation should be suspected by the coronary artery spasm [9]. Intraoperative or postoperative coronary spasms are referable to the coronary artery trauma during manipulation, compression by the drains, electrolytes disturbance or releasing factors [9-11]. Sometimes, spasm occurs during the cardiopulmonary bypass weaning, but mostly, resuscitation and intraaortic balloon pumps are needed in the postoperative period.

Although the right coronary artery was not compressed preoperatively, aortic valve replacement could have made anatomical change to the relationships between anomalous coronary artery and the major vessels. Considering the recovery of vital signs postoperatively, blood volume changes in the heart and the major vessels, during the $\mathrm{CPB}$ weaning period, could have affected that relationship. Postoperative angiography was not considered necessary because vital signs were stable.

The incidences of anomalous origin of the coronary artery is about $0.6-2 \%[12,13]$ and the most common types are the anomalous circumflex origin from the right coronary artery or the right sinus of Valsalva. Anomalous right coronary origin from the left coronary sinus, anomalous left coronary origin from the right coronary artery, or sinus of Valsalva and both coronary arteries from a single ostium were reported. The majorities of these anomalies are benign, but sometimes they result in severe myocardial ischemia, infarction, and sudden death $[14,15]$. Especially, they are vulnerable to compression, insufficiency and injury during valve surgery $[4,13]$. Considering that the coronary artery anomaly is accompanied more commonly in patients with aortic valve pathology [2], anesthesiologists should always be reminded about these complications.

In the cases of mechanical obstruction, routine valve rotation or adequate coronary button mobilization should be considered. However, usually the rescue bypass grafts are needed. When intraoperative coronary artery spasm is expected, intravenous or intracoronary injection of nitrates and calcium antagonists can relieve the spasm $[9,10]$, and intracoronary 
injection of ergonovine can be used as a diagnostic tool. Treatments are intracoronary or intravascular nitroglycerin injection or resuscitative bypass grafts. Maintenance of high perfusion pressure can quickly resolve the coronary air embolism, but particulates embolus needs a rescue graft, but particulates embolus needs a rescue graft. Echocardiography, electrocardiography, angiography can help the diagnosis for the embolism.

Authors didn't think about the possibilities of compression of the right coronary artery because there was no compression preoperative angiography. Excluding other possible causes of unstable vital signs, aberrant coronary artery can be taken into consideration. Conclusively, anesthesiologists should always take care for the coronary artery anatomy, even though it is a valve surgery, and especially since they have anomalous origins or pathologies.

\section{References}

1. Luciani GB, Casali G, Mazzucco A. Risk factors for coronary complications after stentless aortic root replacement. Semin Thorac Cardiovasc Surg 1999; 11(4 Suppl 1): 126-32.

2. O'Blenes SB, Feindel CM. Aortic root replacement with anomalous origin of the coronary arteries. Ann Thorac Surg 2002; 73: 647-9.

3. Kincaid EH, Cordell AR, Hammon JW, Adair SM, Kon ND. Coronary insufficiency after stentless aortic root replacement: risk factors and solutions. Ann Thorac Surg 2007; 83: 964-8.

4. Alsaddique AA, Elsaegh MM, Fouda MA. Aortic valve replacement in a patient with an aberrant left coronary artery. Asian Cardiovasc Thorac Ann 2003; 11: 169-70.

5. Fernández AL, El-Diasty MM, Martínez A, Alvarez J, García-Bengochea JB. A simple technique to rule out occlusion of right coronary artery after aortic valve surgery. Ann Thorac Surg 2011; 92: 2281-2.

6. Koh TW, Ferdinand FD, Jin XY, Gibson DG, Pepper JR. Coronary artery problems during homograft aortic valve replacement: role of transesophageal echocardiography. Ann Thorac Surg 1997; 64: 533-5.

7. Salerno TA, Bergsland J, Calafiore AM, Cordell AR, Kon ND, Bhayana JN. Acute right ventricular failure during aortic valvular operation due to mechanical problem in the right coronary artery. Ann Thorac Surg 1996; 61: 706-7.

8. Somerville J, Ross D. Homograft replacement of aortic root with reimplantation of coronary arteries. Results after one to five years. Br Heart J 1982; 47: 473-82.

9. Pinho T, Almeida J, Garcia M, Pinho P. Coronary artery spasm following aortic valve replacement. Interact Cardiovasc Thorac Surg 2007; 6: 387-8.

10. Pragliola C, Altamura L, Niccoli G, Siviglia M, De Paulis S, Possati GF. Postoperative coronary artery spasm complicating aortic valve replacement: implications for identification and treatment. Ann Thorac Surg 2007; 83: 670-2.

11. Ellis EF, Oelz O, Roberts LJ 2nd, Payne NA, Sweetman BJ, Nies AS, et al. Coronary arterial smooth muscle contraction by a substance released from platelets: evidence that it is thromboxane A2. Science 1976; 193: 1135-7.

12. Kimbiris D, Iskandrian AS, Segal BL, Bemis CE. Anomalous aortic origin of coronary arteries. Circulation 1978; 58: 606-15.

13. Vaishnava P, Pyo R, Filsoufi F, Sharma S. Compression of an anomalous left circumflex artery after aortic and mitral valve replacement. Ann Thorac Surg 2011; 92: 1887-9.

14. Zhou ZJ, Kaviraj B, Cao SP, Wang YG, Huang Z, Guo ZG, et al. Management of subacute myocardial infarction in a patient with left coronary artery originating from the right coronary artery. Nan Fang Yi Ke Da Xue Xue Bao 2011; 31: 1295-7.

15. Parker JA, Peivandi AA, Bitschnau S, Kayhan N, Vahl CF. Anomalous origin and retropulmonary course of an atherosclerotic stenosed left circumflex coronary artery. Int J Vasc Med 2010; 2010: 490858. 